\title{
Birt-Hogg-Dubé syndrome
}

INSERM

\section{Source}

INSERM. (1999). Orphanet: an online rare disease and orphan drug data base. Birt-Hogg-

Dubé syndrome. ORPHA:122

Birt-Hogg-Dube (BHD) syndrome is characterized by skin lesions, kidney tumors, and pulmonary cysts that may be associated with pneumothorax. It is a rare clinicopathologic condition named after the three Canadian physicians who reported the syndrome in 1977. 